\title{
Pengaruh Terapi Relaksasi Otot Progresif terhadap Respon Fisiologis Pasien Hipertensi
}

\author{
Ni Luh Putu Ekarini ${ }^{1}$ Heryati $^{2}$, Raden Siti Maryam ${ }^{3}$ \\ 1,2,3 Jurusan Keperawatan, Politeknik Kesehatan Kemenkes Jakarta III, Indonesia \\ Email: ekaputu98@yahoo.com
}

\begin{abstract}
Effect of Progressive Muscle Relaxation Therapy on the Physiological Response of Hypertensive Patients. Hypertension is one type of non-communicable disease, which is increasing every year. Hypertension is a condition where systolic blood pressure $\geq 140 \mathrm{mmHg}$ and/ or diastolic blood pressure $\geq 90 \mathrm{mmHg}$. Today the treatment of disease including hypertension has been widely modified between pharmacological therapy and non-pharmacological therapy. One of the non-pharmacological therapies currently used is relaxation therapy in a deep breath and progressive muscle relaxation. This study was to determine the effect of progressive muscle relaxation therapy on the physiological response of hypertensive patients at Cipayung Health Center, East Jakarta. The research design used was a quasi-experimental pre-test post-test with control group design. The number of research samples was 37 respondents in the intervention group and 37 respondents for the control group. The results showed that there was a difference in diastolic blood pressure between the intervention group and the control group after progressive muscle relaxation intervention $(\mathrm{p}$-value $=0,000)$.
\end{abstract}

Keywords: Hypertension, Physiological response, Progressive muscle relaxation therapy

\begin{abstract}
Abstrak: Pengaruh Terapi Relaksasi Otot Progresif terhadap Respon Fisiologis Pasien Hipertensi. Hipertensi merupakan salah satu jenis penyakit tidak menular yang kejadiannya setiap tahun terus meningkat. Hipertensi adalah suatu keadaan dimana tekanan darah sistolik $\geq 140$ $\mathrm{mmHg}$ dan atau tekanan darah diastolik $\geq 90 \mathrm{mmHg}$. Dewasa ini pengobatan suatu penyakit termasuk hipertensi sudah banyak dimodifikasi antara terapi farmakologi dengan terapi non farmakologi. Salah satu terapi non farmakologi yang saat ini banyak digunakan adalah terapi relaksasi napas dalam dan relaksasi otot progresif. Penelitian ini bertujuan mengetahui pengaruh terapi relaksasi otot progresif terhadap respon fisiologis pasien hipertensi di Puskesmas Cipayung Jakarta Timur. Desain penelitian quasi eksperimen dengan rancangan pre-test post-test with control group. Jumlah sampel penelitian 37 responden kelompok intervensi dan 37 responden untuk kelompok kontrol. Hasil penelitian menunjukkan bahwa terdapat perbedaan tekanan darah diastolik antara kelompok intervensi dan kelompok kontrol setelah dilakukan intervensi relaksasi otot progresif $(p=0,000)$.
\end{abstract}

Kata kunci: Hipertensi, Respon fisiologis, Terapi relaksasi otot progresif

\section{PENDAHULUAN}

Hipertensi merupakan suatu kondisi medis yang kronis dimana tekanan darah meningkat diatas tekanan darah yang disepakati normal. Tekanan darah terbentuk dari interaksi antara aliran darah dan tahanan pembuluh darah perifer. Tekanan darah meningkat dan mencapai puncak apabila aliran darah deras misalnya pada waktu sistol, kemudian menurun pada waktu aliran darah berkurang seperti pada waktu diastol. Data epidemiologi menunjukkan bahwa peningkatan tekanan darah sistolik dan atau tekanan darah diastolik atau tekanan nadi meningkatkan kejadian kardiovaskular (Kabo, 2010).
WHO mencatat terdapat satu milyar orang di dunia menderita hipertensi, dua pertiga di antaranya berada di negara berkembang yang berpenghasilan rendah-sedang. Prevalensi hipertensi akan terus meningkat tajam, diprediksi pada tahun 2025 nanti, sekitar $29 \%$ orang dewasa di seluruh dunia menderita hipertensi. Hipertensi telah mengakibatkan kematian sekitar 8 juta orang setiap tahun, 1,5 juta kematian terjadi di Asia Tenggara, yang sepertiga populasinya menderita hipertensi (Kemenkes, 2013).

Prevalensi hipertensi di Indonesia didapat melalui pengukuran pada umur $\geq 18$ tahun sebesar 25,8 persen, tertinggi di Bangka Belitung $(30,9 \%)$, diikuti Kalimantan Selatan $(30,8 \%)$, 
Kalimantan Timur $(29,6 \%)$ dan Jawa Barat $(29,4 \%)$. Prevalensi hipertensi di Indonesia yang didapat melalui kuesioner terdiagnosis tenaga kesehatan sebesar 9,4 persen, yang didiagnosis tenaga kesehatan atau sedang minum obat sebesar $9,5 \%$. Jadi ada $0,1 \%$ yang minum obat sendiri. Responden yang mempunyai tekanan darah normal tetapi sedang minum obat hipertensi sebesar $0.7 \%$. Jadi prevalensi hipertensi di Indonesia sebesar 26,5\%. Prevalensi hipertensi di DKI Jakarta yang didapat melalui kuesioner terdiagnosis tenaga kesehatan sebesar $10 \%$, yang didiagnosis tenaga kesehatan atau sedang minum obat sebesar $10,1 \%$ dan yang hipertensi dari pengukuran sebesar 20\%. Dengan demikian angka kejadian hipertensi di DKI masih tinggi dan terus mengalami peningkatan setiap tahunnya (Balitbangkes, 2013).

Peningkatan angka kejadian hipertensi dikarenakan penyakit ini tidak memberikan keluhan dan gejala yang khas sehingga banyak penderita tidak menyadarinya. Orang dengan riwayat hipertensi perlu dimodifikasi agar kontrol dan memakai obat dengan teratur. Pengobatan suatu penyakit sudah banyak dimodifikasi antara terapi farmakologi dengan terapi non farmakologi. Salah satu terapi non farmakologi yang saat ini banyak digunakan adalah terapi relaksasi. Teknik relaksasi digunakan untuk mengurangi stres dan membantu untuk berbagai penyakit kronis seperti sakit kepala, sindroma iritasi pencernaan, hipertensi, aritmia penyakit inflamasi pencernaan dan nyeri otot. Respon relaksasi merupakan suatu keadaan umum dimana terjadi penurunan kognitif, fisiologis dan atau perilaku. Relaksasi juga menyebabkan menurunnya gairah. Proses relaksasi dapat memanjangkan serabut otot, impuls pengiriman ke otak dan penurunan aktifitas pada otak dan sistem tubuh lainnya. Penurunan frekuensi jantung dan napas, tekanan darah, konsumsi oksigen serta meningkatnya aktifitas otak dan temperatur kulit perifer merupakan beberapa respon dari relaksasi. Terapi relaksasi dapat membantu individu mengembangkan keterampilan kognitif untuk menurunkan energi negatif serta berespon sesuai dengan lingkungan sekitar (Perry \& Potter, 2009).

Terapi relaksasi yang sering digunakan antara lain imagery, meditasi, biofeedback, hipnoterapi, musik, yoga, prayer, herbal, aromaterapi, terapi pijat dan terapi energi (deWitt \& O’Neill, 2014). Terapi relaksasi memberikan pengaruh pada penurunan gejala psikologi seperti depresi dan ansietas, mendukung kontrol diri dan rasa percaya diri, menurunkan manifestasi simpatis yang ditunjukkan dengan penurunan variabel hemodinamik dan kardiovaskuler serta menurunkan kejadian penyakit jantung karena iskemik miokard pada pasien hipertensi, infark miokard dan penyakit jantung koroner. Pada terapi latihan fisik, beberapa studi melaporkan pengaruh positif dari latihan aerobik, latihan ketahanan dan atau latihan jalan dapat mengektifkan penggunaan oksigen, ketahanan otot dan meningkatkan toleransi aktifitas pada pasien gagal jantung. Terapi relaksasi dan latihan fisik efektif meningkatkan kesehatan psikologis dan fisiologis pada pasien gagal jantung. Selanjutnya bisa digunakan sebagai perawatan modalitas individu untuk program manajemen penyakit (Doris et al, 2007).

Terapi obat bukan satu-satunya alternatif terapi yang dapat dipilih tetapi, diperlukan sebuah terapi pendamping untuk mengurangi ketergantungan terhadap obat untuk mempertahankan kualitas hidup penderita hipertensi. Alternatif terapi lain yang sering digunakan adalah terapi relaksasi. Terapi relaksasi disini tidak dimaksudkan untuk mengganti terapi obat yang selama ini digunakan penderita hipertensi, terapi ini hanya membantu untuk menimbulkan rasa nyaman atau relaks. Dalam keadaan relaks, tubuh melalui otak akan memproduksi endorphin yang berfungsi sebagai analgesik alami tubuh dan dapat meredakan rasa nyeri (keluhan-keluhan fisik). Selain itu dalam keadaan relaks tubuh akan mengaktifkan sistem saraf parasimpatis yang berfungsi untuk menurunkan detak jantung, laju pernapasan dan tekanan darah (Sulistyarini, 2013).

Relaksasi otot progresif adalah teknik sistematis untuk mencapai keadaan relaksasi dimana metode yang ditetapkan melalui metode progresif dengan tahap latihan berkesinambungan. Relaksasi otot progresif dapat dilakukan dengan cara menegangkan dan melemaskan otot skeletal sehingga otot menjadi relaks dan mengurangi tingkat stres serta pengobatan untuk menurunkan tekanan darah pada penderita hipertensi (Wardani, 2015).

Hasil penelitian Handayani dan Rahmayati (2018) menyatakan bahwa relaksasi otot progresif efektif menurunkan kecemasan pre operatif. Begitu pula dengan hasil penelitian adanya pengaruh massase pada tangan dan kaki yang memberikan efek relaksasi pada penderita hipertensi (Udani, 2016).

\section{METODE}

Penelitian ini merupakan penelitian kuasi eksperimen dengan rancangan Pre-test Post-test 
with Control Group. Pada desain penelitian ini dilakukan observasi pertama (pre-test) pada kelompok perlakuan (intervensi) dan kelompok kontrol. Kemudian kedua kelompok diikuti pengukuran kedua (post-test) dan hasil pengukuran akan dibandingkan dengan hasil pengukuran pada kelompok pembanding (kontrol) yang tidak menerima perlakuan. Adapun kriteria inklusi adalah pasien usia dewasa yang datang ke Posyandu Lansia dengan riwayat hipertensi serta minum obat anti hipertensi, pasien dalam kondisi sehat (stabil) dan memungkinkan untuk dilakukan pengambilan data, dapat membaca, menulis, bersedia diwawancarai dan melakukan relaksasi otot progresif. Kriteria eksklusi antara lain pasien usia dewasa yang datang ke Puskesmas untuk berobat dan menolak ikut penelitian, pasien ada gangguan fisik dan kognitif dan tidak bisa mengikuti latihan relaksasi. Teknik pengambikan sampel dengan cara purposive sampling dari populasi terjangkau. Penentuan besar sampel menggunakan uji beda 2 mean dengan jumlah sampel penelitian 37 responden kelompok intervensi dan 37 responden untuk kelompok kontrol.

Analisis data dilakukan melalui analisis univariat untuk jenis kelamin, pendidikan, pekerjaan, riwayat menderita hipertensi, riwayat keluarga yang menderita hipertensi, obat yang digunakan dan pasien tinggal serumah. Analisis bivariat untuk mengetahui pengaruh variabel independen (usia, jenis kelamin, pendidikan, pekerjaan, riwayat menderita hipertensi, riwayat keluarga yang menderita hipertensi, obat yang digunakan dan tinggal serumah) dan variabel dependen (tekanan darah, frekuensi nadi, frekuensi napas) setelah dilakukan terapi relaksasi otot progresif. Analisis menggunakan uji $T$ dependent dan uji $T$ indenpendent.

\section{HASIL}

\section{Analisis Univariat}

Tabel 1. Karakteristik Responden berdasarkan Usia

\begin{tabular}{lcccrc}
\hline Kelompok & n & Mean & Med & SD & \multicolumn{1}{c}{$\begin{array}{c}\text { Min- } \\
\text { Max }\end{array}$} \\
\hline Intervensi & 37 & 65.89 & 65 & 8.313 & $46-79$ \\
Kontrol & 37 & 53.92 & 55 & 11.121 & $33-80$ \\
\hline
\end{tabular}

Pada tabel 1 diketahui bahwa Mean usia pada kelompok intervensi yaitu sekitar 65,89 tahun, usia termuda 46 tahun dan tertua 79 tahun. Sedangkan pada kelompok kontrol mean usia responden 53,92 tahun dengan usia termuda 33 tahun dan tertua 80 tahun.

Tabel 2. Distribusi Karakteristik Responden dengan Hipertensi dan Keluarga yang Tinggal Bersama Responden

\begin{tabular}{|c|c|c|c|c|c|c|}
\hline \multirow{2}{*}{ Variabel } & \multicolumn{2}{|c|}{ Kel.Intervensi } & \multicolumn{2}{|c|}{ Kel.Kontrol } & \multicolumn{2}{|c|}{ Total } \\
\hline & n & $\%$ & n & $\%$ & $\mathbf{n}$ & $\%$ \\
\hline \multicolumn{7}{|l|}{ Jenis Kelamin } \\
\hline 1. Laki-laki & 3 & 8,1 & 6 & 16,2 & 9 & 12,2 \\
\hline 2. Perempuan & 34 & 91,9 & 31 & 83,8 & 65 & 87,8 \\
\hline \multicolumn{7}{|l|}{ Suku } \\
\hline 1. Sunda & 5 & 13,5 & 3 & 8,1 & 8 & 10,8 \\
\hline 2. Betawi & 26 & 70,3 & 18 & 48,6 & 44 & 59,5 \\
\hline 3. Jawa & 6 & 16,3 & 11 & 29,7 & 17 & 22,9 \\
\hline 4. Lain2 & - & - & 5 & 11,5 & 5 & 6,8 \\
\hline \multicolumn{7}{|l|}{ Pendidikan } \\
\hline 1. $\mathrm{SD}$ & 31 & 83,8 & 8 & 21,6 & 39 & 52,8 \\
\hline 2. SMP & 1 & 2,7 & 7 & 18,9 & 8 & 10,8 \\
\hline 3. SMA & 5 & 13,5 & 13 & 35,1 & 18 & 24,3 \\
\hline 4. D3 & - & - & 2 & 5,4 & 2 & 2,7 \\
\hline 5. $\mathrm{S} 1$ & - & - & 3 & 8,1 & 3 & 4 \\
\hline 6. $\mathrm{S} 2$ & - & - & 4 & 10,8 & 4 & 5,4 \\
\hline \multicolumn{7}{|l|}{ Pekerjaan } \\
\hline 1. Tidak Kerja & 12 & 32,4 & 10 & 27 & 22 & 29,7 \\
\hline 2. IRT & 24 & 64,9 & 17 & 45,9 & 41 & 55,5 \\
\hline 3. Swasta & - & - & 4 & 10,8 & 4 & 5,4 \\
\hline 4. Wiraswasta & 1 & 2,7 & 1 & 2,7 & 2 & 2,7 \\
\hline 5. PNS & - & - & 2 & 5,4 & 2 & 2,7 \\
\hline 6. Lain-lain & - & - & 3 & 8,1 & 3 & 4 \\
\hline \multicolumn{7}{|l|}{ Riw. Hipertensi } \\
\hline 1. $<12$ bulan & 12 & 32,4 & 3 & 8,1 & 15 & 20,3 \\
\hline 2. > 1 thn & 19 & 51,4 & 16 & 43,2 & 35 & 47,3 \\
\hline 3. Tidak Ingat & 6 & 16,2 & 18 & 48,6 & 24 & 32,4 \\
\hline \multicolumn{7}{|l|}{ Riw. Penyakit } \\
\hline lain & 22 & 59,5 & 30 & 81,1 & 52 & 70,3 \\
\hline 1. Tidak ada & 1 & 2,7 & 1 & 2,7 & 2 & 2,7 \\
\hline 2. Ginjal & 1 & 2,7 & 1 & 2,7 & 2 & 2,7 \\
\hline 3. Stroke & 13 & 35,1 & 5 & 13,5 & 18 & 24,3 \\
\hline 4. Lain-lain & & & & & & \\
\hline \multicolumn{7}{|l|}{$\begin{array}{l}\text { Riw. Keluarga } \\
\text { sakit Hipertensi }\end{array}$} \\
\hline 1. Tidak ada & 22 & 59,5 & 16 & 43,2 & 38 & 51,4 \\
\hline 2. Ayah & 7 & 18,9 & 15 & 40,5 & 22 & 29,7 \\
\hline 3. Ibu & 6 & 16,2 & 4 & 10,8 & 10 & 13,5 \\
\hline 4. Nenek & - & - & 1 & 2,7 & 1 & 1,4 \\
\hline $\begin{array}{l}\text { 5. Saudara } \\
\text { sekandung }\end{array}$ & 2 & 5,4 & 1 & 2,7 & 3 & 4 \\
\hline \multicolumn{7}{|l|}{$\begin{array}{l}\text { Keluarga yg } \\
\text { tinggal serumah }\end{array}$} \\
\hline 1. Suami/istri & 17 & 45,9 & 21 & 56,8 & 38 & 51,4 \\
\hline 2. Anak & 20 & 54,1 & 13 & 35,1 & 33 & 44,5 \\
\hline 3. Menantu & - & - & 1 & 2,7 & 1 & 1,4 \\
\hline 4. Saudara & - & - & 2 & 5,4 & 2 & 2,7 \\
\hline
\end{tabular}




\section{Analisis Bivariat}

Tabel 3. Tekanan Darah Sistolik, Tekanan Darah Diastolik dan Frekuensi Nadi Responden Sebelum dan Sesudah Intervensi pada Kelompok Intervensi dan Kontrol

\begin{tabular}{|c|c|c|c|c|c|c|}
\hline Variabel & Kelompok & Mean & SD & $95 \% \mathrm{CI}$ & $\mathbf{t}$ & p-value \\
\hline Tekanan Darah & Kel. Intervensi & & & & & \\
\hline \multirow[t]{7}{*}{ Sistolik } & Sebelum & 142,41 & 13,520 & $9,408-2,759$ & 1,108 & 0,275 \\
\hline & Sesudah & 145,73 & 19,936 & & & \\
\hline & Selisih & 3,324 & & & & \\
\hline & Kel. Kontrol & & & & & \\
\hline & Sebelum & 125,51 & 24,734 & $7,895-9,462$ & 0,183 & 0,856 \\
\hline & Sesudah & 124,73 & 14,811 & & & \\
\hline & Selisih & 0,784 & & & & \\
\hline \multirow{8}{*}{ Diastolik } & Kel. Intervensi & & & & & \\
\hline & Sebelum & 83,81 & 9,092 & $8,881-0,016$ & 2,021 & 0,051 \\
\hline & Sesudah & 88,24 & 9,737 & & & \\
\hline & Selisih & 4,432 & & & & \\
\hline & Kel. Kontrol & & & & & \\
\hline & Sebelum & 77,81 & 8,181 & $1,276-2,303$ & 0,582 & 0,564 \\
\hline & Sesudah & 77,30 & 6,078 & & & \\
\hline & Selisih & 0,514 & & & & \\
\hline \multirow[t]{8}{*}{ Frekuensi Nadi } & Kel. Intervensi & & & & & \\
\hline & Sebelum & 84,03 & 6,994 & $5,006-3,439$ & 0,376 & 0,709 \\
\hline & Sesudah & 84,81 & 10,982 & & & \\
\hline & Selisih & 0,784 & & & & \\
\hline & Kel. Kontrol & & & & & \\
\hline & Sebelum & 84,03 & 5,984 & $1,121-4,717$ & 3,293 & 0,002 \\
\hline & Sesudah & 81,11 & 4,551 & & & \\
\hline & Selisih & 2,919 & & & & \\
\hline
\end{tabular}

Tabel 4. Perbedaan Tekanan Diastolik Responden Sesudah Intervensi antar Kelompok

\begin{tabular}{lllrrrrr}
\hline Variabel & Kelompok & n & Mean & \multicolumn{1}{c}{ SD } & 95\% CI & F & p-value \\
\hline Tekanan & Intervensi & 37 & 4,43 & 13,343 & $9,702-0,190$ & 23,265 & 0,000 \\
Diastolik & Kontrol & 37 & 0,51 & 5,368 & & & \\
\hline
\end{tabular}

Hasil analisis menunjukkan bahwa terdapat perbedaan tekanan darah diastolik antara kelompok intervensi dan kelompok kontrol setelah dilakukan intervensi relaksasi otot progresif (nilai $p=0,000$ ).

\section{PEMBAHASAN}

Rata-rata usia pada kelompok intervensi dan kontrol sama-sama berada pada rentang usia dewasa menengah (40-65 tahun) dimana pada usia tersebut kejadian hipertensi juga makin meningkat. Hasil ini sejalan dengan hasil Riskesdas (2013) yaitu angka kejadian hipertensi mengalamai peningkatan seiring dengan meningkatnya usia mulai dari 45 tahun keatas sampai usia diatas 75 tahun (Balitbangkes, 2013).

Karakteristik responden pada kedua kelompok intervensi dan kontrol yaitu perempuan, suku Betawi, pendidikan Sekolah Dasar, bekerja sebagai Ibu Rumah Tangga, memiliki riwayat hipertensi lebih 1 tahun, tidak memiliki penyakit lainnya, tidak ada riwayat keluarga dengan hipertensi dan tinggal serumah dengan suami. Hasil Riskesdas 2013 menunjukkan bahwa hipertensi lebih banyak pada perempuan, status pendidikan tidak sekolah dan status pekerjaan tidak bekerja (Balitbangkes, 2013). Ada sedikit perbedaan pada status pekerjaan yang juga bisa mengandung arti yang sama dimana hasil penelitian ini menunjukkan pekerjaan lebih banyak ibu rumah tangga yang juga bisa diartikan hampir sama dengan tidak bekerja. Sejalan juga dengan jenis kelamin yang lebih banyak perempuan. Angka kejadian hipertensi lebih banyak terjadi pada perempuan terutama setelah menopause karena berkurangnya hormon estrogen yang bisa berpengaruh pada tekanan darah.

Hal ini mendukung hasil penelitian dimana rata-rata usia responden baik pada kelompok intervensi dan kontrol yang berada pada rentang usia diatas 50 tahun dan pada usia tersebut sudah mengalami menopause. Buku kesehatan yang dimiliki pasien dimana data tekanan darah setiap bulan ada pada rentang normal dengan konsumsi obat antihipertensi dan belum banyak yang 
memodifikasi dengan terapi non farmakologi. Responden yang minum obat antihipertensi pagi hari, pada saat diukur tekanan darah sebagian besar dalam rentang normal sedangkan responden yang minum obat antihipertensi malam, saat diukur tekanan darah banyak yang mengalami peningkatan. Responden sebagian besar tidak ada riwayat penyakit lain dan tidak ada riwayat hipertensi dari keluarga serta sebagian besar tinggal bersama pasangan.

Adanya perbedaan usia antara kelompok intervensi dan kelompok kontrol. Hasil analisis ini menunjukkan bahwa latihan relaksasi otot progresif dapat dilakukan pada semua rentang usia bukan hanya pada usia dewasa tua saja karena latihan relaksasi ini bukan merupakan latihan fisik berat dan bisa dilakukan dengan posisi apapun juga baik berbaring, duduk ataupun berdiri. Latihan relaksasi otot progresif ini lebih baik lagi dilakukan pada usia yang lebih muda karena banyak sekali hasil positif dari latihan yang dilakukan. Pada orang dengan riwayat hipertensi, latihan ini merupakan salah satu teknik pengobatan non farmakologi yang bisa dikombinasi dengan pengobatan medis. Respon relaksasi ditandai dengan menurunnya detak jantung dan angka metabolik dan dengan menurunnya tekanan darah pada orang yang mengidap hipertensi (Sari \& Murtini, 2015).

Relaksasi yang dilakukan pada individu yang mengalami hipertensi ditujukan untuk mengurangi stres yang dapat menyebabkan meningkatnya tekanan darah serta ketegangan pada otot-otot seluruh tubuh. Relaksasi pernapasan dalam dapat membantu individu menurunkan stres. Pernapasan yang tepat dapat menurunkan stres dan kebiasaan bernapas yang tepat penting untuk kesehatan mental serta fisik. Kekurangan oksigen dalam darah memperbesar kemungkinan terjadinya kelelahan dan stres yang dialami menjadi teratasi. Relaksasi pernapasan dalam menggunakan teknik pernapasan menitikberatkan bernapas dengan tenang dan dalam (Sari \& Murtini, 2015).

Hasil analisis menunjukkan terdapat perbedaan bermakna tekanan darah diastolik pada kelompok intervensi sebelum dan sesudah intervensi (nilai $p=0,051$ ), dengan selisih nilai rata-rata sebesar 4,432 Sedangkan pada kelompok kontrol tidak ada perbedaan bermakna tekanan darah diastolik (nilai $p=0,564$ ). Adanya perbedaan bermakna tekanan darah diastolik pada kelompok intervensi menunjukkan bahwa relaksasi otot progresif cukup efektif menurunkan tekanan darah pada saat terjadi kontraksi melewati katup atrioventrikular trikuspidalis dan bikuspidalis. Hasil penelitian ini sejalan dengan hasil penelitian dari Tawaang, et al (2013) yang menyatakan bahwa teknik relaksasi napas dalam dapat menurunkan tekanan darah sistol dan diastol pada pasien hipertensi sedang-berat. Latihan Slow Deep Breathing juga dapat menurunkan tekanan darah dan kecemasan pada pasien hipertensi primer dengan rata-rata penurunan $15,5 \mathrm{mmHg}$ pada tekanan darah sistol dan rata-rata penurunan $9,9 \mathrm{mmHg}$ pada tekanan darah diastol (Sepdianto et al, 2007).

Adanya perbedaan bermakna frekuensi nadi pada kelompok kontrol sebelum dan sesudah intervensi $(p=0,002)$ dengan selisih rata-rata nadi sebesar 2,919. Sedangkan pada kelompok intervensi tidak ada perbedaan bermakna frekuensi nadi $(p=0,709)$. Respon relaksasi ditandai dengan menurunnya detak jantung dan angka metabolik dengan menurunnya tekanan darah pada orang yang mengidap hipertensi (Sari \& Murtini, 2015). Adanya perbedaan frekuensi nadi pada kelompok kontrol yang hanya dilatih napas dalam saja dapat disebabkan karena pasien hipertensi lebih fokus melakukan latihan napas dalam sehingga suplai oksigen ke seluruh tubuh terpenuhi dan aliran darah balik ke jantung lancar sehingga berpengaruh juga pada frekuensi nadi. Relaksasi napasdalam terdiri atas latihan dan praktik pernapasan yang dirancang dan dijalankan untuk mencapai ventilasi yang lebih terkontrol dan efisien untuk mengurangi kerja pernapasan. Latihan pernapasan dapat meningkatkan pengembangan paru sehingga ventilasi alveoli meningkat (Wardani, 2015).

Hasil analisis menunjukkan bahwa terdapat perbedaan tekanan darah diastolik antara kelompok intervensi dan kelompok kontrol setelah dilakukan intervensi relaksasi otot progresif $(p=0,000)$. Adanya perbedaan tekanan darah diastolik pada kelompok intervensi dan kontrol bisa disebabkan karena adanya sedikit perbedaan perlakuan pada kedua kelompok. Pada kelompok kontrol hanya dilakukan latihan napas dalam sementara pada kelompok intervensi latihan napas dalam dipadukan dengan latihan relaksasi otot progresif sehingga tekanan darah diastolik juga bisa berbeda. Tekanan diastolik ini dihasilkan pada saat darah melewati katup atrioventrikular trikuspidalis dan bikuspidalis. Tekanan darah sistol yang dihasilkan saat darah melewati katup pulmonalis dan aorta tidak ada perbedaan karena darah yang dialirkan menuju ke paru-paru dan seluruh tubuh. 


\section{SIMPULAN}

Adanya perbedaan bermakna frekuensi nadi pada kelompok kontrol sebelum dan sesudah intervensi dan adanya perbedaan tekanan darah diastolik pada kelompok intervensi dan kontrol setelah diberikan terapi relaksasi otot progresif ditambah dengan latihan napas dalam.

\section{DAFTAR PUSTAKA}

Badan Penelitian dan Pengembangan Kesehatan Departemen Kesehatan RI. (2013). Riset Kesehatan Dasar. Jakarta: CV. Kiat Nusa.

DeWit, S.C. \& O'Neill, P. (2014). Fundamentals Concepts and Skills for Nursing. 4th Edition. USA: Elsevier Saunders.

Doris, S. F., Lee, D. T., Woo, J., \& Hui, E. (2007). Non-pharmacological interventions in older people with heart failure: effects of exercise training and relaxation therapy. Gerontology, 53(2), 74-81.

Handayani, R.S. \& Rahmayati, E. (2018). Pengaruh Aromaterapi Lavender, Relaksasi Otot Progresif dan Guided Imagery terhadap Kecemasan Pasien Pre Operatif. Jurnal Kesehatan, Volume 9, Nomor 2, hlm 319324. Tersedia: https://ejurnal.poltekkestjk.ac.id/index.php/JK/article/view/680. DOI: http://dx.doi.org/10.26630/jk.v9i2.

Kabo, P. (2010). Bagaimana Menggunakan ObatObat Kardiovaskular Secara Rasional. Jakarta: Balai Penerbit Fakultas Kedokteran Universitas Indonesia.

Kemenkes RI. (2013). Pedoman Teknis Penemuan dan Tatalaksana Hipertensi. Jakarta: Direktorat Pengendalian Penyakit Tidak Menular.

Potter, P. \& Perry, A. G. (2009). Fundamentals of Nursing (Seventh Ed). Singapura: Mosby Elsevier.

Sari, H. F., \& Murtini, M. (2015). Relaksasi Untuk Mengurangi Stres Pada Penderita
Terapi relaksasi otot progresif dapat dilaksanakanterpadu dengan kegiatan Posyandu Lansia atau Prolanis dengan menekankan pada aspek promotif dan preventif terhadap pasien yang mempunyai riwayat hipertensi. Pelayanan difokuskan pada pasien yang melakukan kontrol secara rutin untuk menekan dan mengurangi kejadian komplikasi lanjut dari hipertensi.

Hipertensi Esensial. Humanitas: Jurnal Psikologi Indonesia, 12(1), 12-28.

Sepdianto, T. C., Nurachmah, E., \& Gayatri, D. (2010). Penurunan tekanan darah dan kecemasan melalui latihan slow deep breathing pada pasien hipertensi primer. Jurnal Keperawatan Indonesia, 13(1), 37-41.

Sulistyarini, I. (2013). Terapi relaksasi untuk menurunkan tekanan darah dan meningkatkan kualitas hidup penderita hipertensi. Jurnal psikologi, 40(1), 28-38.

Tawaang, E., Mulyadi, N., \& Palandeng, H. (2013). Pengaruh Teknik Relaksasi Napas Dalam Terhadap Penurunan Tekanan Darah Pada Pasien Hipertensi Sedang-berat Di Ruang Irina C Blu Prof. Dr. RD Kandou Manado. Jurnal Keperawatan, 1(1).

Udani, G. (2016). Pengaruh Massase pada Penderita Hipertensi di UPTD Panti Tresna Werdha Lampung Selatan. Jurnal Kesehatan, Volume VII, Nomor 3. Tersedia: https://ejurnal.poltekkestjk.ac.id/index.php/JK/article/view/680. DOI: http://dx.doi.org/10.26630/jk.v9i2.

Wardani, D.W. (2015). Pengaruh Teknik Relaksasi Nafas Dalam Sebagai Terapi Tambahan Terhadap Penurunan Tekanan Darah Pada pasien Hipertensi Tingkat 1 Semarang. (Skripsi, Universitas Negeri Semarang). 